\title{
Analysis and evaluation of vibration characteristics of a new type of electric mini-tiller based on vibration test
}

\author{
Po Niu, Jian Chen*, Jindou Zhao, Zeyong Luo \\ (College of Engineering and Technology, Southwest University, Chongqing 400715, China)
}

\begin{abstract}
Now the internal combustion engine mini-tiller has become the main and indispensable agricultural machinery in vast hilly and mountainous areas of Southwest China. However, its intense vibration may pose a big threat to operators. As a countermeasure to the tiller vibration, a new type of electric mini-tiller powered with a group of lithium battery and a brushless DC motor was developed. The vibration signals at the handle of the tiller were tested under 6 conditions as follows: the tiller was under states of static and working in the field, at slow, medium and rapid speed, respectively. The signals were processed by means of the time domain eigenvalue analysis and the frequency spectrum analysis. The results show that with the electric motor rated speed increased from 95 to $140 \mathrm{r} /$ min under static conditions, the RMS values increased $122.54 \%$, and with the forward speed increased from 0.30 to $0.80 \mathrm{~m} / \mathrm{s}$ under working conditions, the RMS values increased $201.78 \%$. When the tiller was working, the first order vibration frequencies were $25.99 \mathrm{~Hz}, 26.99 \mathrm{~Hz}$ and $28.99 \mathrm{~Hz}$ at slow, medium and rapid speed respectively, all not within 37.50-65.00 Hz, the sensitive range of human hands to the vibration frequency. In addition, according to the results of hand transmitted vibration analysis, it can be found that compared with operating the internal combustion engine mini-tiller under the same working condition, the onset of vibration-induced white finger can be delayed for 3.70 years to 10.20 years by operation of the new electric tiller.
\end{abstract}

Keywords: electric mini-tiller, vibration characteristics, time domain analysis, frequency domain analysis, hand transmitted vibration

DOI: $10.25165 /$ j.jijabe.20191205.4737

Citation: Niu P, Chen J, Zhao J D, Luo Z Y. Analysis and evaluation of vibration characteristics of a new type of electric mini-tiller based on vibration test. Int J Agric \& Biol Eng, 2019; 12(5): 106-110.

\section{Introduction}

Being small volume, light weight, simple structure and easy transfer in the farm land, the internal combustion engine mini-tiller has become the main and indispensable agricultural machinery in vast hilly and mountainous area of Southwest China, where arable fields are small, fragmented and rugged, and usually, there are not roads for tractors traffic ${ }^{[1]}$. However, intense vibration of the tiller may cause injuries to sensory nerves, muscles, bones and joints, influence the operators' performance capability, or present a serious health and safety risk to the operators ${ }^{[2-4]}$.

Many researches have been done in order to better understand the mechanism of agricultural machinery vibration transmitted to human hands from its excitation sources, and find a way to reduce vibration $^{[5-8]}$ or improve the operator's working conditions ${ }^{[9-11]}$. Dewangan et al. pointed that the vibration energy absorption (VEA) may provide a better indication of vibration-induced injuries than would a measure of the handle vibration spectrum ${ }^{[12]}$. Sam and Kathirvel developed a new type of vibration isolators for engine, handle bar and handle were developed to increase the safe exposure level of operators ${ }^{[13]}$. Kalra et al. ${ }^{[14]}$ explored a low-cost system

Received date: 2018-10-29 Accepted date: 2019-08-27

Biographies: Po Niu, PhD Candidate, research interest: modern agricultural equipment, Email: niupo205@163.com; Jindou Zhao, PhD Candidate, research interest: modern agricultural equipment, Email: jindouzhao@swu.edu.cn; Zeyong Luo, Master student, research interest: modern agricultural equipment, Email: 13640525662@163.com.

*Corresponding author: Jian Chen, PhD, Professor, research interest: modern agricultural equipment. College of Engineering and Technology, Southwest University, Chongqing 400715, China. Tel: +86-13628384705, Email: jianchen@swu.edu.cn. for measurement of coupling forces imposed by the hand on a handle under static and dynamic conditions, and its feasibility for applications to hand-held power tools. Liang et al. ${ }^{[15]}$ selected 1Z-105 diesel mini tiller as a prototype, its vibration characteristics was analyzed in the time and frequency domains and the effects on the human body were explored, and suggestion was made regarding the handling comfort of the mini tiller. But these researches have little effect, the main reasons lie in that both a decrease in the vibration caused by two coupling effects of the engine and rotary blade rollers and obstruction of vibration transmission are difficult without a substantial increases in size, weight and price of the tiller $^{[16,17]}$. Such increases, however, are not acceptable to farmers, because the size and weight involve directly with the convenience in operation and transfer of the machine and the price influences the profit.

Therefore, as an alternative one, a new type of electric mini-tiller was developed. The tiller differs fully from the majority of those already studied in being able to meet the tillage depth demand of $10 \mathrm{~cm}$ or more, rather than just for shallow tillage and weeding in greenhouses ${ }^{[18,19]}$

In this study, the vibration characteristics at the handle of the newly developed electric mini-tiller were studied and analyzed, so as to provide a valuable reference method and references for the study of vibration characteristics at handrails of mini-tillers and similar agricultural machinery.

\section{Materials and methods}

\subsection{Materials}

\subsubsection{Test time and area}

The test was conducted from 10:00 am to 1:00 pm on February 1,2018 in a farm plot, with a length of $30 \mathrm{~m}$ and a width of $15 \mathrm{~m}$, 
located at Longquan village, Zhongliang town, Shapingba district, Chongqing, China $\left(106^{\circ} 23^{\prime} 45^{\prime \prime} \mathrm{E}, 2^{2} 39^{\prime} 45^{\prime \prime} \mathrm{N}, 500 \mathrm{~m}\right.$ above sea level). The soil bulk density, moisture rate and soil compaction in the middle part of the plot except the ridge around it are relatively consistent, and the soil parameters were listed in Table 1.

Table 1 Soil parameters

\begin{tabular}{lc}
\hline \multicolumn{1}{c}{ Soils } & Parameter value \\
\hline Soil texture & Sandy loam \\
Soil bulk density $/ \mathrm{g} \cdot \mathrm{cm}^{-3}$ & 2.65 \\
Moisture rate $/ \%$ & 20.61 \\
Soil compaction in depth of $0-50 \mathrm{~mm} / \mathrm{MPa}$ & $0-0.196$ \\
Soil compaction in depth of $50-100 \mathrm{~mm} / \mathrm{MPa}$ & $0.196-0.438$ \\
Soil compaction in depth of $100-150 \mathrm{~mm} / \mathrm{MPa}$ & $0.201-0.467$ \\
\hline
\end{tabular}

2.1.2 Structure and parameters of the electric mini-tiller

The newly developed electric mini-tiller, as shown in Figure 1, is composed mainly of handrail, motor controller, electric motor, battery pack, rotary blade roller, transmission system, frame, and depth control device. Among them, handrail, rotary blade roller, frame, and depth control device are as same as those in the traditional internal combustion engine tiller. However, a $60 \mathrm{~V}$ 20 Ah lithium battery and a $750 \mathrm{~W}$ brushless DC motor are introduced to replace the internal combustion engine. One pair of bevel gears is used to transmit power from motor to rotary blade roller. A motor speed controller is installed on the handle is applied to change tiller speed. The parameters of the tiller were listed in Table 2.

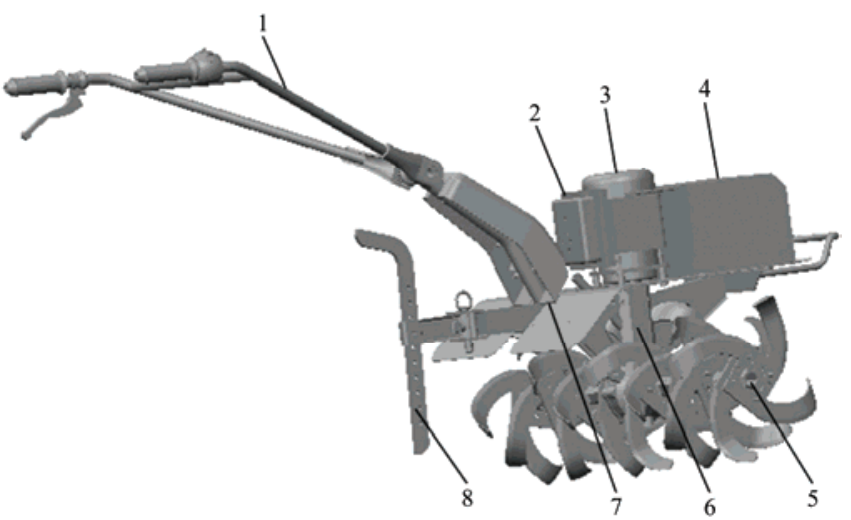

1. Handrail 2. Motor controller 3. Electric motor 4. Battery pack 5. Rotary blade roller 6. Transmission system 7. Frame 8. Depth control device

Figure 1 Electric mini-tiller

Table 2 Parameters of the electric mini-tiller

\begin{tabular}{lc}
\hline \multicolumn{1}{c}{ Item } & Value \\
\hline Mass/kg & $\leq 50$ \\
Tillage width/cm & 70 \\
Tillage depth/cm & $\geq 10$ \\
Transmission type & Direct drive and three forward speeds \\
Battery model & 60V20Ah lithium battery \\
Electric motor & Brushless DC Motor \\
Rated power of electric motor $/ \mathrm{kW}$ & 0.75 \\
Type of the blade & Machete \\
No. of blades & $4 \times 3$ \\
\hline
\end{tabular}

\subsubsection{Instruments}

Soil compaction meter (SC900, Spectrum Technologies, Inc., USA), three-dimensional acceleration sensor (356A16, PCB company, USA), and data acquisition card (NI9234, NI company, USA) were used, as shown in Figure 2. Their key parameters were listed in Table 3.

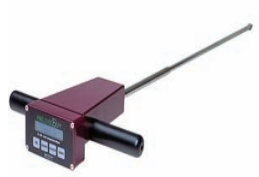

a. Soil compaction meter

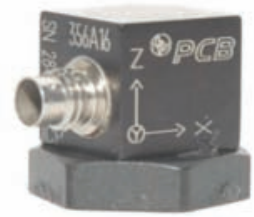

b. Three-dimensional acceleration sensor

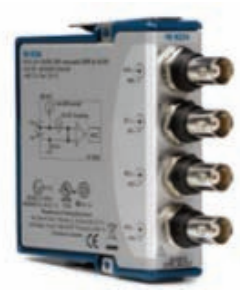

c. Data acquisition card
Figure 2 Test instruments

Table 3 Key parameters of soil penetrometer, sensor and data acquisition card

\begin{tabular}{clc}
\hline \multicolumn{1}{c}{ Device } & \multicolumn{1}{c}{ Parameters } & Value \\
\hline \multirow{2}{*}{$\begin{array}{c}\text { SC900 Soil compaction } \\
\text { meter }\end{array}$} & Depth range $/ \mathrm{mm}$ & $0-7000$ \\
& Resolution $/ \mathrm{kPa}$ & $0-450$ \\
& Depth $\mathrm{precision} / \mathrm{mm}$ & 35 \\
& Range $/ \mathrm{g}$ & 12.5 \\
\hline \multirow{2}{*}{ 356A16 three-dimensional } & Frequency $/ \mathrm{kHz}$ & \pm 50 \\
acceleration sensor & Sensitivity $/ \mathrm{mV} \cdot \mathrm{g}{ }^{-1}$ & $0.3-6$ \\
& Transverse sensitivity $/ \%$ & 100 \\
& Mass $/ \mathrm{g}$ & $<5$ \\
NI9234 data & Dynamic range $/ \mathrm{dB}$ & 7.4 \\
\hline acquisition card & Input voltage $/ \mathrm{V}$ & 102 \\
& Digital signal $\mathrm{rate} / \mathrm{kHz}$ & 51.2 \\
\hline
\end{tabular}

\subsection{Methodologies}

Figure 3 showed the outline of the study. Firstly, the vibration acceleration values and vibration frequency obtained from the vibration signal at the handle of the electric mini-tiller were collected and processed by NI9234 data acquisition card and LabVIEW Signal Express. Then, the vibration characteristics of the tiller were analyzed from the RMS values and the vibration frequency. Finally, the hand transmitted vibration of the tiller was evaluated by the exposure duration of vibration-induced white finger, with the tiller working in the filed $4 \mathrm{~h} / \mathrm{d}$ and a risk of probability appearance of $10 \%$.

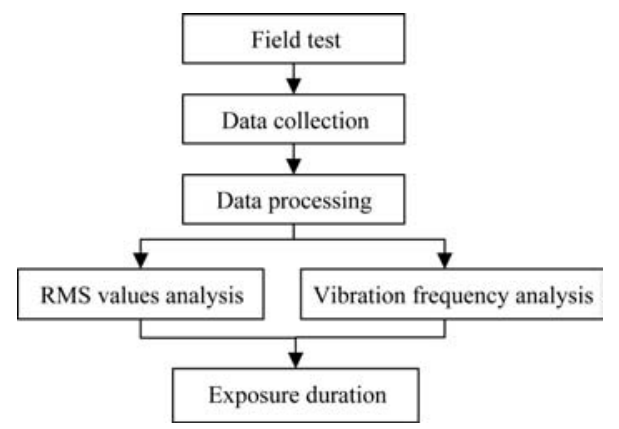

Figure 3 Outline of the study

2.2.1 Field test

Six test conditions were chosen, as shown in Table 4.

Table 4 Test plan arrangement

\begin{tabular}{cccc}
\hline $\begin{array}{c}\text { Test } \\
\text { condition }\end{array}$ & $\begin{array}{c}\text { Rotation speed of rotary } \\
\text { blade roller/r/min }\end{array}$ & $\begin{array}{c}\text { Forward } \\
\text { speed/m/s }\end{array}$ & State of mini-tiller \\
\hline I & Slow $/ 52.5$ & 0 & Static (the rotary blade \\
roller idling) \\
II & Medium $/ 87.5$ & 0 & \\
III & Rapid $/ 140$ & 0 & Working in the field (the \\
IV & Slow $/ 52.5$ & 0.3 & rotary blade roller cutting \\
V & Medium $/ 87.5$ & 0.5 & soil) \\
VI & Rapid/140 & 0.8 & \\
\hline
\end{tabular}


The acceleration sensor was fixed on the handle. The $X, Y$ and $Z$ directions of sensor correspond to the vertical, the for-and-aft and the left-to-right direction, respectively, as shown in Figure 4. The NI 9234 data acquisition card collected the vibration acceleration signals at the handle from the sensor and transmitted them to LabVIEW Signal Express. Then vibration acceleration signals at the handle under six conditions were recorded, and the duration of each recording was $30 \mathrm{~s}$. The filed test was shown in Figure 5 .

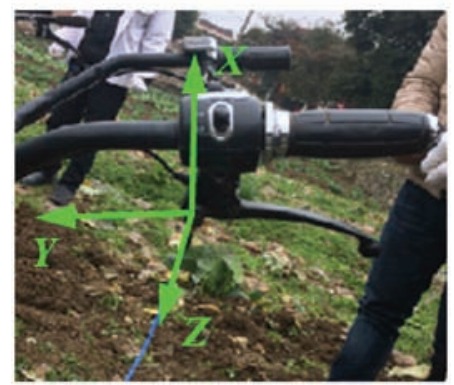

Figure 4 Corresponding relation of $X, Y, Z$ directions

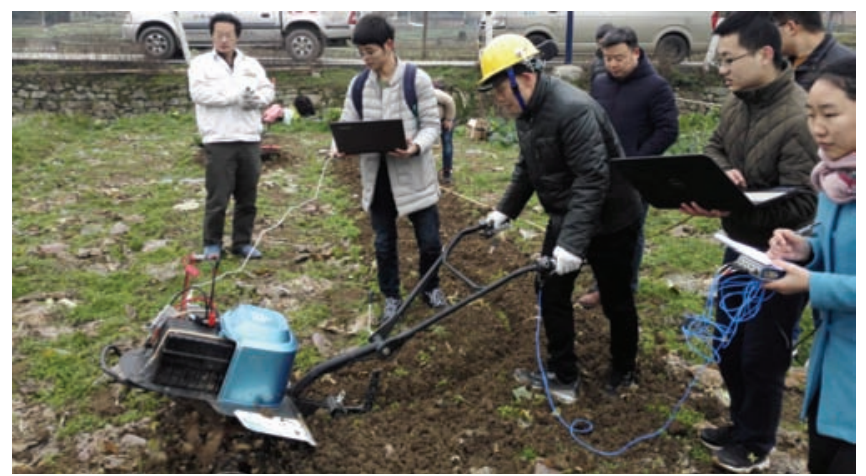

Figure 5 Field test

\subsubsection{Signal processing}

As the tiller vibration is continuous, it can be described by the statistical characteristic values. In this study, the RMS (root-mean-square) values were used to represent the vibration acceleration values, and they were obtained from the vibration signal processing by time domain analysis. Then, the frequency domain characteristics were obtained from the time domain signals processing by the filtering and Fast Fourier Transforming. Vibration frequency ranging from $2 \mathrm{~Hz}$ to $200 \mathrm{~Hz}$ was focused on for the analysis, with the weighting factor $W_{\mathrm{h} i}$ greater than 0.1 within the frequency range (The weighting factor $W_{\mathrm{h} i}$ is related to the vibration frequency, and can be derived from ISO 5349-1: 2001 (Table A.2) $)^{[20,21]}$.

\subsubsection{Assessment of hand transmitted vibration}

According to the previous studies, the hand transmitted vibration of mini-tiller is usually evaluated by the exposure duration of vibration-induced white finger, with the operator used the tiller working $4 \mathrm{~h}$ in the field and $8 \mathrm{~h}$ per day under usual conditions, and the risk of vibration-induced white finger appearance is $10 \%{ }^{[20-22]}$.

The vibration total value $a_{\mathrm{hv}}\left(\mathrm{m} / \mathrm{s}^{2}\right)$ is the comprehensive of the vibration value of all three axis $(x, y, z)$, can be calculated by:

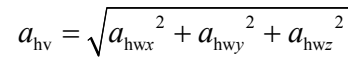

where, $a_{\mathrm{hw} x}, a_{\mathrm{hw} y}$ and $a_{\mathrm{hwz}}$ are frequency weighted acceleration values for the $x, y$ and $z$ axis respectively, and can be calculated by:

$$
a_{\mathrm{hw} k}=a_{k} W_{\mathrm{h} i}
$$

where, $a_{k}$ is the RMS values in $k$ axis, $\mathrm{m} / \mathrm{s}^{2},(k$ is one of $x, y, z$ axis); $W_{\mathrm{h} i}$ is the weighting factor.
The daily vibration exposure is expressed in terms of the daily energy-equivalent frequency-weighted vibration total value as:

$$
A(0)=a_{\mathrm{hv}}\left[\frac{T}{T_{0}}\right]
$$

where, $A(0)$ is vibration total value, $\mathrm{m} / \mathrm{s}^{2} ; T$ is the total daily duration of exposure to the vibration $a_{\mathrm{hv}}, \mathrm{h}$; and $T_{0}$ is the reference duration, $\mathrm{h}$.

In this study, $4 \mathrm{~h}$ working in the field in $8 \mathrm{~h}$ per day under usual conditions was chosen for analysis, the daily vibration exposure $A(8)$ as:

$$
A(8)=\frac{\sqrt{2}}{2} a_{\mathrm{hv}}
$$

If the risk of vibration-induced white finger appearance is $10 \%$, the exposure duration can be calculated by:

$$
D_{\mathrm{y}}=31.8[A(8)]^{-1.06}
$$

where, $D_{\mathrm{y}}$ is exposure duration, year

\section{Results}

\subsection{RMS values}

The vibration acceleration signals at the handle were recorded under six test conditions, and the signals in $X$ direction under condition IV were shown in Figure 6. The RMS values under different conditions were shown in Table 5.

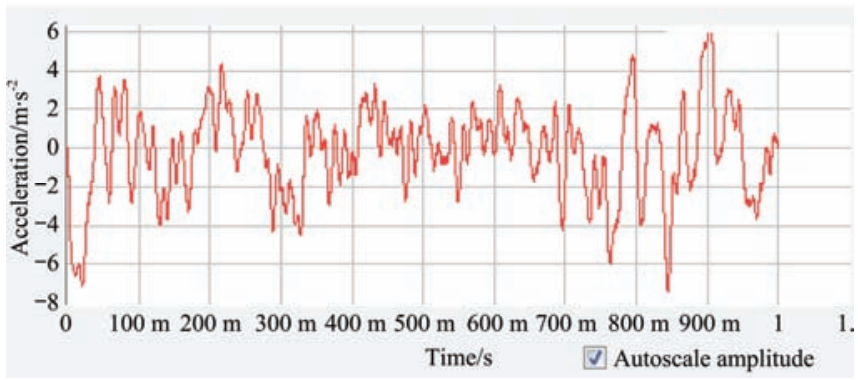

Figure 6 Vibration acceleration signals at the handle in $X$ direction under condition IV

Table 5 The average RMS values at the handle for each condition

\begin{tabular}{ccccccc}
\hline \multirow{2}{*}{ Direction } & \multicolumn{5}{c}{ Test condition } \\
\cline { 2 - 7 } & $\mathrm{I} / \mathrm{m} \cdot \mathrm{s}^{-2}$ & $\mathrm{II} / \mathrm{m} \cdot \mathrm{s}^{-2}$ & $\mathrm{III} / \mathrm{m} \cdot \mathrm{s}^{-2}$ & $\mathrm{IV} / \mathrm{m} \cdot \mathrm{s}^{-2}$ & $\mathrm{~V} / \mathrm{m} \cdot \mathrm{s}^{-2}$ & $\mathrm{VI} / \mathrm{m} \cdot \mathrm{s}^{-2}$ \\
\hline$X$ & 0.94 & 1.26 & 1.42 & 2.32 & 4.93 & 5.04 \\
$Y$ & 0.71 & 1.18 & 1.39 & 2.52 & 5.25 & 7.14 \\
$Z$ & 1.06 & 1.39 & 1.58 & 3.67 & 6.13 & 7.21 \\
\hline
\end{tabular}

From Table 5, the RMS values trend were as follows: when the tiller under static conditions, with the electric motor rotation speed increased from $95 \mathrm{r} / \mathrm{min}$ to $140 \mathrm{r} / \mathrm{min}$, the RMS values increased from $0.94 \mathrm{~m} / \mathrm{s}^{2}$ to $1.42 \mathrm{~m} / \mathrm{s}^{2}$, or increasing by $51.06 \%$ in $X$ direction, increased from $0.71 \mathrm{~m} / \mathrm{s}^{2}$ to $1.39 \mathrm{~m} / \mathrm{s}^{2}$, or increasing by $95.77 \%$ in $Y$ direction, and increased from $1.06 \mathrm{~m} / \mathrm{s}^{2}$ to $1.58 \mathrm{~m} / \mathrm{s}^{2}$, or increasing by $49.06 \%$ in $Z$ direction, which increased the most in $X$ direction, and the least in $Z$ direction; when the tiller under working conditions, with the forward speed increased from $0.3 \mathrm{~m} / \mathrm{s}$ to $0.8 \mathrm{~m} / \mathrm{s}$, the RMS values increased from $2.32 \mathrm{~m} / \mathrm{s}^{2}$ to $5.04 \mathrm{~m} / \mathrm{s}^{2}$ in $X$ direction, increasing by $117.24 \%$, increased from $2.52 \mathrm{~m} / \mathrm{s}^{2}$ to $7.14 \mathrm{~m} / \mathrm{s}^{2}$ in $Y$ direction, increasing by $183.33 \%$ and increased from $3.67 \mathrm{~m} / \mathrm{s}^{2}$ to $7.21 \mathrm{~m} / \mathrm{s}^{2}$ in $Z$ direction, increasing by $96.46 \%$, which increased the most in $Y$ direction, and the least in $Z$ direction.

\subsection{The vibration frequency}

As an example, the vibration spectrogram at the handle in $X$ direction condition IV is shown in Figure 7. The first order 
vibration frequencies and amplitude values at the handle under static and working conditions were listed in Table 6 .

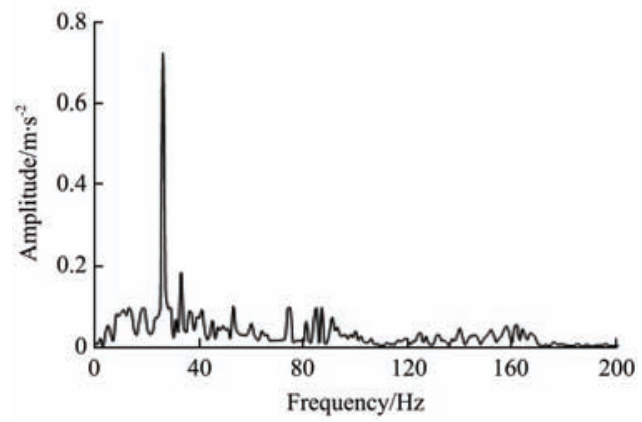

Figure 7 Vibration spectrogram at the handle in $X$ direction under condition IV

Table 6 The first order vibration frequencies and amplitude values

\begin{tabular}{|c|c|c|c|c|c|c|}
\hline \multirow[b]{2}{*}{$\begin{array}{c}\text { Test } \\
\text { condition }\end{array}$} & \multicolumn{2}{|c|}{ Direction $X$} & \multicolumn{2}{|c|}{ Direction $Y$} & \multicolumn{2}{|c|}{ Direction $Z$} \\
\hline & $\begin{array}{c}\text { Vibration } \\
\text { frequency } \\
\quad / \mathrm{Hz}\end{array}$ & $\underset{/ \mathrm{m} \cdot \mathrm{s}^{-2}}{\text { Amplitude }}$ & $\begin{array}{c}\text { Vibration } \\
\text { frequency } \\
/ \mathrm{Hz}\end{array}$ & $\begin{array}{l}\text { Amplitude } \\
/ \mathrm{m} \cdot \mathrm{s}^{-2}\end{array}$ & $\begin{array}{c}\text { Vibration } \\
\text { frequency } \\
/ \mathrm{Hz}\end{array}$ & $\underset{/ \mathrm{m} \cdot \mathrm{s}^{-2}}{\text { Amplitude }}$ \\
\hline I & 45.98 & 0.68 & 45.98 & 0.34 & 45.98 & 0.62 \\
\hline II & 47.99 & 0.81 & 47.99 & 0.52 & 47.99 & 0.73 \\
\hline III & 48.97 & 1.01 & 48.97 & 0.59 & 48.97 & 0.86 \\
\hline IV & 25.99 & 0.72 & 25.99 & 0.38 & 25.99 & 1.45 \\
\hline $\mathrm{V}$ & 26.99 & 1.11 & 26.99 & 2.54 & 26.99 & 1.78 \\
\hline VI & 28.99 & 1.81 & 28.99 & 4.01 & 28.99 & 2.43 \\
\hline
\end{tabular}

As can be seen from Table 6, the first order vibration frequencies were $45.8 \mathrm{~Hz}, 47.99 \mathrm{~Hz}$ and $48.97 \mathrm{~Hz}$ when the tiller under conditions of I, II and III. The amplitude values increased from $0.68 \mathrm{~m} / \mathrm{s}^{2}$ to $1.01 \mathrm{~m} / \mathrm{s}^{2}$ in $X$ direction, $0.34 \mathrm{~m} / \mathrm{s}^{2}$ to $0.59 \mathrm{~m} / \mathrm{s}^{2}$ in $Y$ direction and $0.62 \mathrm{~m} / \mathrm{s}^{2}$ to $0.89 \mathrm{~m} / \mathrm{s}^{2}$ in $Z$ direction, and the value in $X$ direction was the biggest in all directions under each condition.

When the tiller was under conditions of IV, V and VI, the first order vibration frequencies were $25.99 \mathrm{~Hz}, 26.99 \mathrm{~Hz}$ and $28.99 \mathrm{~Hz}$ respectively. The amplitude values increased from $0.72 \mathrm{~m} / \mathrm{s}^{2}$ to $1.81 \mathrm{~m} / \mathrm{s}^{2}$ in $X$ direction, $0.38 \mathrm{~m} / \mathrm{s}^{2}$ to $0.41 \mathrm{~m} / \mathrm{s}^{2}$ in $Y$ direction and $1.45 \mathrm{~m} / \mathrm{s}^{2}$ to $2.43 \mathrm{~m} / \mathrm{s}^{2}$ in $Z$ direction. Under condition $\mathrm{IV}$, the amplitude value $1.45 \mathrm{~m} / \mathrm{s}^{2}$ in $Z$ direction was the biggest in all directions; under condition $\mathrm{V}, 2.54 \mathrm{~m} / \mathrm{s}^{2}$ was the biggest in $Y$ direction; under condition VI, $4.01 \mathrm{~m} / \mathrm{s}^{2}$ was the biggest in $Z$ direction.

The rotary blade roller cutting soil increased the damping of the tiller, which resulted in the vibration frequencies of static conditions higher than those of working conditions and the amplitude values lower at the same rotation speed. Under slow speed, the vibration frequencies decreased from $45.98 \mathrm{~Hz}$ to $25.99 \mathrm{~Hz}$, the amplitude values increased from $0.68 \mathrm{~m} / \mathrm{s}^{2}$ to $0.72 \mathrm{~m} / \mathrm{s}^{2}$ in $X$ direction, $0.34 \mathrm{~m} / \mathrm{s}^{2}$ to $0.38 \mathrm{~m} / \mathrm{s}^{2}$ in $Y$ direction and $0.62 \mathrm{~m} / \mathrm{s}^{2}$ to $1.45 \mathrm{~m} / \mathrm{s}^{2}$ in $Z$ direction, which increased the most in $Z$ direction, $133.87 \%$, and the least in $X$ direction, $5.88 \%$; under medium speed, the vibration frequencies decreased from $47.99 \mathrm{~Hz}$ to $26.99 \mathrm{~Hz}$, the amplitude values increased from $0.81 \mathrm{~m} / \mathrm{s}^{2}$ to $1.11 \mathrm{~m} / \mathrm{s}^{2}$ in $X$ direction, $0.52 \mathrm{~m} / \mathrm{s}^{2}$ to $2.54 \mathrm{~m} / \mathrm{s}^{2}$ in $Y$ direction and $0.73 \mathrm{~m} / \mathrm{s}^{2}$ to $1.78 \mathrm{~m} / \mathrm{s}^{2}$ in $Z$ direction, which increased the most in $Y$ direction, about $388.46 \%$ and the least in $X$ direction, $37.04 \%$; under the condition of rapid speed, the vibration frequencies decreased from $48.97 \mathrm{~Hz}$ to $28.99 \mathrm{~Hz}$, the amplitude values increased from $1.01 \mathrm{~m} / \mathrm{s}^{2}$ to $1.81 \mathrm{~m} / \mathrm{s}^{2}$ in $X$ direction, $1.59 \mathrm{~m} / \mathrm{s}^{2}$ to
$4.01 \mathrm{~m} / \mathrm{s}^{2}$ in $Y$ direction and $0.83 \mathrm{~m} / \mathrm{s}^{2}$ to $2.43 \mathrm{~m} / \mathrm{s}^{2}$ in $Z$ direction, which increased the most in $Y$ direction, about $152.20 \%$ and the least in $X$ direction, $79.21 \%$.

\subsection{Exposure duration}

The vibration frequencies (Table 6) were processed by one-third-octave band magnitudes, according to ISO 5349-1: 2001 (Table A.2), the weighting factor $W_{\mathrm{h} i}$ took 0.647 when the tiller was operated at slow and medium speed, and 0.519 at rapid speed.

The vibration total value $a_{\mathrm{hv}}$, the daily vibration exposure $A(8)$, and the exposure duration $D_{\mathrm{y}}$ can be calculated by Table 5 and (Equations (1), (2), (4) and (5)), and the results under working conditions were listed in Table 7.

Table 7 The $a_{\mathrm{hv}}, A(8)$ and $D_{\mathrm{y}}$ for working conditions

\begin{tabular}{cccc}
\hline Test condition & IV & V & VI \\
\hline$a_{\mathrm{hv}} / \mathrm{m} \cdot \mathrm{s}^{-2}$ & 3.24 & 6.12 & 5.87 \\
$A(8) / \mathrm{m} \cdot \mathrm{s}^{-2}$ & 2.29 & 4.33 & 4.15 \\
$D_{\mathrm{y}} / \mathrm{y}$ & 13.2 & 6.7 & 7.1 \\
\hline
\end{tabular}

As can be seen from Table 7, under condition IV, the vibration total value and the daily vibration exposure were minimum, $3.24 \mathrm{~m} / \mathrm{s}^{2}$ and $2.29 \mathrm{~m} / \mathrm{s}^{2}$, and the exposure duration of vibration-induced white finger was the longest, for 13.2 years. Under condition $\mathrm{V}$, the vibration total value and the daily vibration exposure were maximum, $6.12 \mathrm{~m} / \mathrm{s}^{2}$ and $4.33 \mathrm{~m} / \mathrm{s}^{2}$, the exposure duration of vibration-induced white finger was the shortest, 6.7 years. Under condition VI, the vibration total value and the daily vibration exposure were maximum, $5.87 \mathrm{~m} / \mathrm{s}^{2}$ and $4.15 \mathrm{~m} / \mathrm{s}^{2}$, the exposure duration of vibration-induced white finger was the shortest, 7.1 years.

\section{Discussions}

The vibration frequency at the handle of internal combustion engine mini-tiller can be obtained from the previous studies. Yang and Meng obtained the first vibration frequency at the handle of GN31 mini-tiller (diesel engine, rated power $3.8 \mathrm{~kW}$ ) was $43.9 \mathrm{~Hz}$ by dynamic simulation of the virtual prototype model ${ }^{[23]}$. $\mathrm{Li}$ et al. obtained the first order vibration frequency at the handle of 1Z-105 mini-tiller (the most popular type in Southwest China, diesel engine, rated power $3.5 \mathrm{~kW}$ ) was $43.05 \mathrm{~Hz}^{[24]}$. According to the relatively sensitive range of human hands to vibration frequency $(37.5-65 \mathrm{~Hz})^{[25]}$, all the vibration frequencies of the mini-tillers in above studies were within the sensitive range. While the first order vibration frequencies at the handle of the electric mini-tiller were $25.99 \mathrm{~Hz}, 26.99 \mathrm{~Hz}$ and $28.99 \mathrm{~Hz}$ (Table 6) when the tiller was operated at slow, medium and rapid speed, respectively. These frequencies were not within the sensitive range of human hands to the vibration frequency.

Tewari et al. ${ }^{[17]}$ and Ragni et al. ${ }^{[26]}$ pointed out that hand transmitted vibration of the mini-tiller was very strong and the operator had a high risk of vibration-induced white fingers. Ragni et al. ${ }^{[26]}$ evaluated the vibration level at the handle for several mini-tillers based on ISO5349, drawing the conclusion that if the risk of pathology appearance was $10 \%$, the vibration-induced white finger will appear after 3 years of continuous use of these machines, under usual working conditions.

The exposure duration were 13.2 years, 6.7 years and 7.1 years (Table 7) when the electric mini-tiller was operated at slow, medium and rapid speed respectively, and delayed 10.2 years, 3.7 years and 4.1 years compared with 3 years of the internal combustion engine mini-tiller. 


\section{Conclusions}

When the electric mini-tiller was under static conditions, with the electric motor rated speed increased from $95 \mathrm{r} / \mathrm{min}$ to $140 \mathrm{r} / \mathrm{min}$, the RMS values at the handle increased $122.54 \%$ (from minimum $0.71 \mathrm{~m} / \mathrm{s}^{2}$ to maximum $1.58 \mathrm{~m} / \mathrm{s}^{2}$ ).

When the electric mini-tiller was working, with the forward speed increased from $0.3 \mathrm{~m} / \mathrm{s}$ to $0.8 \mathrm{~m} / \mathrm{s}$, the RMS values increased $201.78 \%$ (from minimum $2.32 \mathrm{~m} / \mathrm{s}^{2}$ to maximum $7.21 \mathrm{~m} / \mathrm{s}^{2}$ ). The maximum vibration total value was $6.12 \mathrm{~m} / \mathrm{s}^{2}$ when the tiller was operated at medium speed, and the minimum was $3.24 \mathrm{~m} / \mathrm{s}^{2}$ when the tiller was at slow speed.

The rotary blade roller cutting soil increased the damping of the tiller, which resulted in the vibration frequencies of static conditions higher than those of working conditions and the amplitude values lower than those at the same rotation speed. Under working conditions, the vibration frequencies decreased $43.74 \%, 43.76 \%$ and $40.8 \%$, and the amplitude values increased $326.47 \%, 388.46 \%$ and $579.66 \%$ at slow, medium and rapid speed compared with those at the same rotation speed under static conditions.

The first order vibration frequencies of internal combustion engine mini-tiller working in the field within the sensitive range of human hands to vibration frequency $37.5-65 \mathrm{~Hz}$, while the first order vibration frequencies of the electric mini-tiller working were $25.99 \mathrm{~Hz}, 26.99 \mathrm{~Hz}$ and $28.99 \mathrm{~Hz}$ which were not within the sensitive range of human hands to vibration frequency. At the same time, the exposure durations of vibration-induced white finger delayed 10.2 years, 3.7 years and 4.1 years, compared with the exposure duration of 3 years for the internal combustion engine mini-tiller, under the same condition. Therefore, the vibration at the handle of the electric mini-tiller was reduced greatly compared with the internal combustion engine mini-tiller.

\section{Acknowledgements}

This study was financially supported by the Special Projects of Generic Key Technology Innovation in Chongqing's Major Industries (csct2015zdcy-ztzx80003) and the Scientific Research Innovation Projects for Graduate Student of Chongqing (CYB17071).

\section{[References]}

[1] Chen J. Agricultural mechanization in Southwestern China during transitional period: A case study. Agricultural Mechanization in Asia, Africa and Latin America, 2018; 49(1): 7-10, 21.

[2] Rabbani M A, Tsujimoto $T$, Mitsuoka M, Inoueb E, Okayasub $T$. Prediction of the vibration characteristics of half-track tractor considering a three-dimensional dynamic model. Biosystem Engineering, 2011; 110(2): $178-188$.

[3] Ahmadian H, Hassan-Beygi R, Ghobadian B. Determination of a power tiller vibration acceleration envelope curves on transportation mode. International Conference on Mechanical Engineering and Advanced Technology, ICMEAT, 2012.

[4] Kabir Md S N, Chung S-O, Kim Y-J, Sung N-S, Hong S-J. Measurement and evaluation of whole body vibration of agricultural tractor operator. Int J Agric \& Biol Eng, 2017; 10(1): 248-255.
[5] Wang Y X, Osman A N, Zhang D X, Yang L, Cui T, Zhong X J. Optimized design and field experiment of a staggered vibrating subsoiler for conservation tillage. Journal of Vibration and Shock, 2019; 12(1): 59-65.

[6] Niu P, Yang M J, Chen J, Yang L, Xie S Y, Chen X B. Structural optimization of handrail of a handheld tiller by vibration modal analysis. INMATEH-Agricultural Engineering, 2017; 52(2): 91-98.

[7] Fabbri A, Cevoli C, Cantalupo G. A method for handlebars ballast calculation in order to reduce vibration transmissibility in walk behind tractors. Journal of Agricultural Engineering, 2017; 48(2): 81-87.

[8] Xu L Z, Chai X Y, Gao Z P, Li Y M, Wang Y D. Experimental study on driver seat vibration characteristics of crawler-type combine harvester. Int J Agric \& Biol Eng, 2019; 12(2): 90-97.

[9] Griffin M J. Measurement, evaluation, and assessment of peripheral neurological disorders caused by hand-transmitted vibration. International Archives of Occupational and Environmental Health, 2008; 81: 559-573.

[10] Xu G, Zhu S H, Nie X T, He L, Li K. Natural frequencies calculation for vibrating systems of tractors made in China. Journal of Vibration and Shock, 2014; 33(15): 157-161.

[11] Thomas H L, Morten K E, Ario K. Experimental analysis of occupational whole-body vibration exposure of agricultural tractor with large square baler. International Journal of Industrial Ergonomics, 2015; 47: 79-83.

[12] Dewangan K N, Tewari V K. Vibration energy absorption in the hand-arm system of hand tractor operator. Biosystems Engineering, 2009, 103(4): 445-454.

[13] Sam B, Kathirvel K. Development and evaluation of vibration isolators for reducing hand transmitted vibration of walking and riding type power tillers. Biosystems Engineering, 2009; 103(4): 427-437.

[14] Kalra M, Rakheja S, Marcotte P, Dewangan K N, Adewusi S. Measurement of coupling forces at the power tool handle-hand interface. International Journal of Industrial Ergonomics, 2015; 50: 105-120.

[15] Liang X C, Chen J, Wang Z. Research on the vibration of mini-tiller. INMATEH-Agricultural Engineering, 2018; 56(3): 17-24

[16] Bini S, Kathirvel K. Vibration characteristics of walking and riding type power tillers. Biosystems Engineering, 2006; 95(4): 517-528.

[17] Tewari V K, Dewangan K N. Effect of vibration isolators in reduction of workstress during field operation of hand tractor. Biosystems Engineering, 2009; 103(4): 146-158.

[18] Cai K, Zhang J L, Ke X R, Deng J Z, He D Q, Zhong B H. Research on the control system of dual-driven electric rotary tiller. Guangdong Agricultural Sciences, 2013; 14: 179-181. (in Chinese)

[19] Gao H S, Zhu S H, Shi J K, Yang J H, Xu X L, Chang Y L, Chen Y. Development of electric micro-farming machines for green-houses. Journal of Machine Design, 2012; 29(11): 83-87. (in Chinese)

[20] Li L, Lu C, Dai M L, Yang L, Zhao W. The design and research of new environmental motor-driven micro rotary tiller. Journal of Yancheng Institute of Technology: Natural Science Edition, 2017; 37(3): 9-13. (in Chinese)

[21] ISO 5349-a. Mechanical vibration- measurement and evaluation of human exposure to hand transmitted vibration, part 1: general requirements, Geneva, Switzerland, 2001.

[22] ISO 5349-b. Mechanical vibration- measurement and evaluation of human exposure to hand transmitted vibration, part 2: practical guidance for measurement at workplace, Geneva, Switzerland, 2001.

[23] Yang J, Meng X W. Study on vibration mechanism and measures for vibration reducing to the handle of cultivator by virtual prototype technology. Transactions of the CSAM, 2005; 36(2): 39-42. (in Chinese)

[24] Li G, Chen J, Xie H J, Wang S M. Vibration test and analysis of mini-tiller. Int J Agric \& Biol Eng, 2016; 9(3): 97-103.

[25] Wen B C, Liu S Y. Mechanical vibration theory and dynamic design method. Mechanical Industry Press, China, 2002.

[26] Ragni L, Vassalini G, Xu F, Zhang L B. Vibration and noise of small implements for soil tillage. J. Agric. Engng Res, 1999; 74(4): 403-409. 